\title{
Editorial
}

Inflammatory

Intestinal Diseases

\section{The Coming of Age of Inflammatory Bowel Diseases in Asia}

\section{Dario Sorrentino}

IBD Center, Division of Gastroenterology, Virginia Tech Carilion School of Medicine, Roanoke, VA, USA; Department of Clinical and Experimental Medical Sciences, University of Udine School of Medicine, Udine, Italy

Inflammatory bowel diseases (IBD), including Crohn disease (CD) and ulcerative colitis, have traditionally been considered diseases of the Western world (North America, Australia, and Europe), since in other parts of the world, their incidence and prevalence appeared to be much lower in the past several decades. Part of the WestEast gradient has been attributed to the scarcity of reliable epidemiological data in developing countries and to the concomitant prevalence of confounding factors for IBD diagnosis (e.g., intestinal tuberculosis). However, epidemiological differences between East and West have always emerged when taking into account only the most developed Asian countries. In recent years, the rapid economic growth and medical progress in large Asian countries, such as India and China, has made such comparisons even more timely and interesting. What has emerged is that in many parts of Asia - as in Western countries the incidence of IBD is increasing exponentially, while still being lower than in Europe or North America.

In the present issue of the journal, Yang [1] and Kedia and Ahuja [2] revisit this subject in light of recent acquisitions in the field and their own outstanding contributions. Yang [1] highlights a number of differences in Korean patients compared to their Western counterparts, including the greater prevalence of $\mathrm{CD}$ in males, the

\section{KARGER}

(C) 2017 S. Karger AG, Basel

E-Mail karger@karger.com

www.karger.com/iid greater prevalence of perianal disease and infectious complications in CD, as well as a lower prevalence of extraintestinal manifestations and positive family history of IBD [1]. IBD natural history, response to biologic therapy, and disease evolution over time appear similar to those reported in the West. By contrast, in their article, Kedia and Ahuja [2] stress some of the striking similarities between IBD in India and IBD in the Western world, including microbial and (mostly) genetic profiles, disease location, disease phenotype, and incidence of colorectal cancer. Interestingly, most studies [3], including the authors' own, do not confirm the well-known deleterious effect of smoking on CD development and natural history in Asia.

So, does IBD in Asia truly differ from IBD in the Western world? An obvious limitation of general comparisons is that Asia is a much more heterogeneous, large and populated continent than Europe, the USA, and Canada. The local environment, the health-care standards, the prevalence of confounding infectious diseases, the socioeconomic status, and many other factors may vary greatly among individual Asian countries. Hence, it might be more appropriate to compare the West with individual Asian countries. Nevertheless, immigration studies show that the offspring of first-generation immigrants from low-IBD-prevalence Asian countries to high-prevalence

Dario Sorrentino, MD, FRACP

Division of Gastroenterology, 3 Riverside Circle Roanoke, VA 24016 (USA)

E-Mail drsorrentino@ carilionclinic.org 
Western countries acquire the risk of the baseline population [4]. In general, current data, including those presented by Yang [1] and Kedia and Ahuja [2], do suggest a close similarity between patients diagnosed with IBD in Asia and those diagnosed in the Western world, with few notable differences. A final answer might take a long time to come. What seems clear for the moment is that the rising incidence and prevalence of IBD in Asia mirrors that of the Western world - which suggests that improved living conditions (the "hygiene hypothesis") might contribute to disease etiology and pathogenesis in both continents. If that is the case, is it truly worth to continue to contrast (with the due limitations outlined above) IBD in Asia and IBD in Europe and North America? Will these studies clarify disease aspects that will one day lead to better treatments or perhaps a cure of IBD? We do not have an answer to the latter question. What we know - as stressed by both Yang [1] and Kedia and Ahuja [2] - is that the total IBD burden in Asia will likely surpass in the near future that in Western countries, which are already struggling to deal with these life-long, debilitating and extremely expensive diseases. Hence, Asian countries should leverage on the Western experience and be prepared to handle an epidemic of massive proportions in a very short time. As in the West, IBD diagnosis in Asia will remain difficult and often delayed with a negative impact on treatment outcomes [5]. As in the West, IBD costs in Asia will be very high and possibly prohibitive for the lower social classes. As in the West, health-care directives and clinical research in Asia should put a strong emphasis on early diagnosis and possible prevention of these diseases in the near future $[6,7]$.

\section{Disclosure Statement}

Dario Sorrentino has received consulting fees from Abbott/ AbbVie, Schering-Plough, MSD, Janssen Research \& Development, LLC, Centocor Inc., TechLab, Hoffmann-La Roche, Giuliani, Schering-Plough, and Ferring; research grants from AbbVie, Janssen Research \& Development, LLC, Schering-Plough, TechLab, and Centocor and serves in the Speakers Bureau of AbbVie and the National Faculty of Janssen. None of these grants and fees are related to the topic of this article.

\section{Funding Sources}

The article did not receive any funding.

\section{References}

1 Yang SK: How does the epidemiology of inflammatory bowel disease differ between East and West? A Korean perspective. Inflamm Intest Dis 2017, DOI: 10.1159/000454712.

2 Kedia S, Ahuja V: Epidemiology of inflammatory bowel disease in India: the great shift East. Inflamm Intest Dis 2017, DOI: $10.1159 / 000465522$.

3 Ng SC, Tang W, Leong RW, Chen M, Ko Y, Studd C, et al: Environmental risk factors in inflammatory bowel disease: a population based case-control study in Asia-Pacific. Gut 2015;64:1063-1071.

4 Benchimol EI, Mack DR, Guttmann A, Nguyen GC, To T, Mojaverian N, et al: Inflammatory bowel disease in immigrants to Canada and their children: a population-based cohort study. Am J Gastroenterol 2015;110:553-563.

5 Nguyen VQ, Jiang D, Hoffman SN, Guntaka S, Mays JL, Wang A, et al: Impact of diagnos- tic delay and associated factors on clinical outcomes in a US inflammatory bowel disease cohort. Inflamm Bowel Dis 2017, Epub ahead of print.

6 Kaplan GG, Jess T: The changing landscape of inflammatory bowel disease: East meets West. Gastroenterology 2016;150:24-26.

7 Sorrentino D: Preclinical and undiagnosed Crohn's disease: the submerged iceberg. Inflamm Bowel Dis 2016;22:476-486. 